\title{
IT SECURITY READINESS IN DEVELOPING COUNTRIES
}

\author{
Tanzania Case Study
}

\author{
Respickius Casmir and Louise Yngström \\ Department of Computer and Systems Science (DSV), Stockholm University / Royal Institute \\ of Technology, Forum 100, 16440 Kista, Sweden, Fax:46870390 25, si-rc@dsv.su.se and \\ louise@dsv.su.se
}

\begin{abstract}
Much as computer and network security is increasingly becoming a global concern for enterprises, government agencies, academia and even for individuals' home use, still there are some people in some parts of the world who are not even informed of the existence of such a problem. Specifically, of these people are in developing countries. Tanzania is a typical example of the countries in which IT security issues have not been addressed adequately. This was revealed during the course and seminars on IT security conducted in Tanzania in the fall of year 2001. In this paper we shall start by describing the background and current situations of IT and connectivity in the country, followed by a summary discussion of evaluations of the course and seminars. Then we shall cite some of the fatal few reported computer security breach incidents in the country. Finally, we shall discuss what is our next step towards an attempt to deal with the problem.
\end{abstract}

Key words: IT Security, Developing Countries, Security Education and Training

\section{INTRODUCTION}

This paper is part of an ongoing research work by the authors in order to establish typical IT security needs for developing countries upon which we can develop security education program(s) for these countries. The research commenced early in January 2001. In the course of this study, we managed to conduct a short course on IT security to the University of Dar es Salaam students from different academic disciplines. We, also, conducted a seminar on IT security to the IT practitioners from the industries, government 
agencies, and legal firms. We, finally, organised a separate seminar to the University of Dar es Salaam academic and non-academic staff to discuss IT security issues.

\section{BACKGROUND}

In the course of ten years back, Tanzania has experienced a dramatic change in the field of Information and Communications Technology (ICT) [1], [6]. Precisely, we can put it, as it is a cut-off from nothing to something. Before 1994, Tanzania had no Internet connectivity, no cellular phone operations, no Automatic Teller Machines (ATM) bank services, and no even television broadcast (except TV-Zanzibar, which was covering the Isles part of Tanzania only). The only way an ordinary citizen could get news and information both local and International was through radio broadcast and newspapers.

Early in 1994, the first television station was inaugurated in the country. In the mid to end of the same year another TV station came into operation making the count of the TV stations in the country to two. Both TV stations were privately owned. Year 1994, can be termed as the year of "Information and Communication Technology (ICT) Revolution" since it is in the same year the first Cellular phone Company opened its business for the first time in the history of the country. The following year 1995, witnessed the establishment a second cellular phone operator, and two more private Television stations.

It was not until 1996 when for the first time Tanzania became part of the global information network, this is the Internet. The University of Dar es Salaam (www.ucc.co.tz) Computing Centre made it. The Internet link was through VSAT link through Transtel in South Africa, which is a subsidiary of TRANSNET (www.tnet.co.za). This was the first Internet Service Provider (ISP) in the country. A few months later in the same year, a local private Company, in the name of CyberTwiga, established another Internet connection over X.25 packet switched network. Standard Chartered Bank was the first bank in Tanzania to introduce the Automatic Teller Machines (ATM) services in Tanzania in 1996.

\section{CURRENT SITUATION}

Today, there are at least seven Internet Service Providers in Tanzania [11], [7]. The number of TV stations is now seven including one cable TV. Cellular phones operators have increased in number from a single operator in 
1994 to five operators in year 2002 [7]. Banks that are offering ATM services have increased to three in February 2002 when NBC bank inaugurated this kind of service. The other bank offering ATM services in the country is Barclays. A number of banking and financial institutions, Government institutions, private companies and other business organisations have been computerised, and some are in the process of computerizing their Information Systems. The systems that are being computerised include payrolls, library systems, banking and insurance systems, hospital systems, accounting systems, academic registration systems and many more [6].

In a report issued by Accenture, the Markle Foundation, and the United Nations Development Programme (UNDP) public-private partnership (the Digital Opportunity Initiative (DOI)) in July 2001 [1], Tanzania was commended for its effort and progress to towards exploiting the benefits of Information and Communication Technology (ICT). DOI was formed at the G8 Okinawa Summit in July 2000. The report further added that, despite having very low per capita income, Tanzania is preparing to reposition itself in the global network economy. Bold steps are being taken to leverage the benefits of ICT for its national priorities of growth and poverty reduction [13]. Key actions include: the creation of an e-secretariat [6], including key stakeholders to create supportive leadership for ICT development; communications infrastructure improvements, both in the capital city and in secondary towns; and restructuring of the financial sector to sustain a more market-driven economy [8]. As it prepares for the shocks associated with the transition from an agriculture-based economy to a knowledge-based economy, Tanzania hopes to illustrate that starting off on the right foot is the key to leapfrogging or "antelope-jumping" many stages of ICT development [1].

\subsection{International Connectivity}

At the moment, all public data communication providers in the country reach the Internet Backbone via Very Small Aperture Terminal (VSAT) [7]. However, there are prospects that soon or later Tanzania will access the Internet via a high capacity optical fibre backbone network following the completion and inauguration of SAT-3 project [10]. The government of Tanzania through the Ministry Transport and Communications is working to see if Tanzania can get connected to SAT-3 in the near future.

\subsection{SAT-3/WASC/SAFE Project in a Nutshell}

Commissioned in May 2002, SAT-3/WASC/SAFE cable is co-owned by a 36-member consortium formed for construction of the submarine optic fibre cable system [10]. This state-of-the art cable system connects Europe 
with Africa and Asia. Going around Western Africa, South Africa and India from Portugal in Europe before terminating in Malaysia in the Far East, this cable provides enhanced capacity, diversity and connectivity to all the consortium members. The recently commissioned SAT-3/WASC/SAFE submarine cable has been operational since May 27, 2002. The cable system has an ultimate capacity of $120 \mathrm{Gbps}$ that will enable it to convey a total of 5.8 million simultaneous telephone channels. The world's first undersea optic fibre cable system around Africa to Europe and Asia was, officially inaugurated by the Senegalese Head of State Mr Abdoulaye WADE. See Figure 1 for the map of SAT-3.

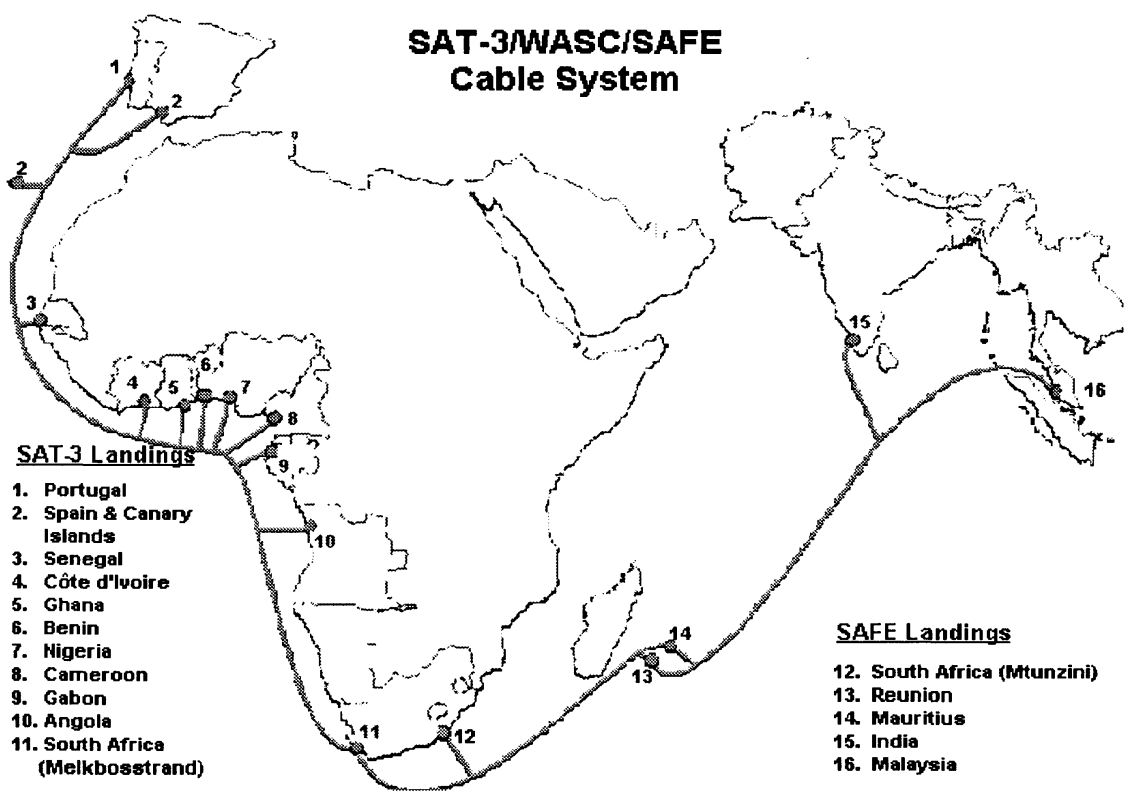

Figure 1. SAT-3/WASC/SAFE Cable System - Completed and inaugurated in 27 May 2002 (Source: http://www.safe-sat3.co.za/configuration.htm [10])

Although Tanzania is not part of this phase, the opportunity to connect to the system exists [7]. There is already a project backed by Transnet, Telekom South Africa, the rail group Africa East Coast and others to lay $2500 \mathrm{KM}$ of optic fibre from Dar es Salaam along the existing railway line to Livingstone in Zambia. The plan is then to link this with a fibre optic cable laid by Namibia Telecommunications from Windhoek to Livingstone, with connections to other east and central African countries planned (Kenya, Uganda, Burundi and Rwanda) [7]. Windhoek already has a high capacity fibre optic link to South Africa that can then connect to SAT-3. 


\section{EVALUATION OF THE COURSE AND SEMINARS}

In the fall of year 2001, we organised a short course on IT security for the University of Dar es Salaam students in Tanzania. The course offering was a result of a collaborative effort between the authors and the department of computer science at the University of Dar es Salaam. All interested students were invited to attend the course from different disciplines at the University. Besides the course, we organised a seminar on IT security for the practitioners from the industry, government agencies, and any interested individuals. We, also, conducted another seminar for academic and nonacademic staff at the University of Dar es Salaam. In both the course and seminars we discussed about general security including security objectives, threats, vulnerabilities, and security services and mechanisms.

These seminars and a course were aimed at giving us an insight of the current scenario, especially, in terms of the level security awareness and IT security readiness for the IT practitioners and academia in the country. Both the seminars and a course were purposely made interactive in that they were dominated by discussions between presenters and the audiences. In all sessions we dedicated an ample time for participants to ask questions and give their comments and suggestions. This enabled us to get the feedback on the feeling and thinking of the people on the subject matter. We, also, distributed questionnaires to the students during the course to get their feedbacks.

\subsection{Course Evaluations}

About 200 students attended a course. This was really beyond our expectations as the course had coincided with the exams period at the University. The course was about IT security overview including the security objectives. Security risks, threats and vulnerabilities were also discussed. On going through the questionnaires, the following were observed:

- Students were very much impressed by the course, and they indicated their appreciation and satisfaction of the material taught and the way they were presented to them

- More than 78\% had no idea about IT security concept

- About $11 \%$ of students said they thought IT security was all about using strong passwords to prevent unauthorised access to data

- More than $85 \%$ proposed IT security to be taught as part of their academic programmes 
- About 58\% of the students wanted to know more about hacking techniques; some said they wanted to become "white hat hackers" in future

- Some students wanted to have hands on training in the implementation of different security mechanisms, especially firewall implementation

- Some wanted to learn more on cryptology in relation to IT security

- Almost all students requested for the course material to be made available, and if possible in electronic form. In response to this, we uploaded both the course material and seminar material into a web server on the net (www.teil.udsm.ac.tz) for them to access. We grated them access to the material through Blackboard application software, an online software for e-learning.

- Almost all students who participated to the course expressed their interests and enthusiasm in learning more on IT security.

\subsection{Seminar Evaluations}

A total of 64 participants attended a seminar on IT security. Initially, we expected to have 50 participants. We made an advert in one of the local newspapers about the seminar one week prior to the event. The response was far beyond our expectations because within two days of the advert, 44 participants had already registered. On the third day all the 50 vacancies were full booked and still more requests for registration were coming in. We had to accept 14 more requests in favour of those who appealed that they couldn't afford to miss such a seminar. Following discussions and comments during the seminar, and the after communications with the seminar participants the following were commented as, there is a need to:

- Conduct regular seminars of the kind in order to raise public awareness on IT security issues

- Introduce IT security to employees at their working places

- Integrate IT security into formal academic programmes in the country

- Educate top managements on the importance of IT security to their organizations

- Incorporate IT security policy into corporate policies

- To develop independent IT security policies for their organizations

\subsection{Further Observations}

- Most of the people who are administering/managing IT/IS systems had different academic backgrounds. While some had a computer science background, others were from engineering, electronics, statistics, 
economics, physics, commerce and management, mathematics and business administration.

- Most of the systems administrators/managers each possesses at least a bachelor degree

- Most of systems administrators have not had formal security education. Their security knowledge is based on security features of specific IT products as specified in the products' manuals. They do not go beyond the scope of a given product.

- Some of the participants complained that it is still too difficult to have top management concern and commitment on security issues, particularly, budgeting for security

- Some of participants thought it were secure enough to install a particular security mechanism such as firewall

- While some of the participants were not much worried about attacks from within their organisations, others were not even aware of such a threat

- Almost all supported an idea from one of the participants to think of forming an association or a society of IT professionals in the country, through which all IT related matters could be discussed on regular basis including IT security issues.

- Participants suggested creating a mailing list, to start with, through which we can exchanges ideas.

- Participants exchanged contacts so that we can keep in touch, and keep posted on security issues.

\subsection{Sense of Insecurity}

To the contrary of our expectations, the seminar had some negative effects to some of the participants. Some people expressed their feelings after the seminar that they felt even more insecure than they thought they were before the seminar. Others wanted to know about some training institutions elsewhere where they could send their systems administrators/managers for some hands on training in IT security. At least two important government institutions requested for some guidelines in developing their own IT security policies. 


\subsection{Summary of Evaluations}

From the discussions, comments and suggestions made during and after the course and seminars, the following were deduced:

1. No single institution is offering IT security skills at any level in the country so far

2. People sees the need for training/education and awareness in IT security

3. People are ready and willing to invest in IT security training

4. The level of security awareness to most of the people is considerably low

5. Since most of the systems administrators/managers are undergraduates, there is a need to develop security curricula at undergraduate level

6. Since there are vast majority of the people out there in the industry interacting with IT/IS systems in their day to day operations without proper training in IT security, this suggests for a need to develop a separate approach to raise their security awareness.

We tried to take each and every comment/opinion from the participants at face value. We did not ignore any because we assumed that every opinion was representing, at least implicitly, a feeling and thinking of a certain group of people in a society, however small that group may be.

\section{REPORTED SECURITY BREACH INCIDENTS}

We managed to get at least two fatal security breach incidents that have been reported to the general public by the high ranked Tanzania government officials.

1. In one incident, at least 1Billion Tanzania Shilling (about 1 Million US\$) was reported to have disappeared or stolen through computer fraud [4]. This was revealed during the Tanzania Parliament sitting in June 2002. The Parliamentary Public Accounts Committee (PAC) says it has uncovered security holes in the government's accounting system through which hundreds of millions of shillings are being quietly stolen using high-tech computer methods. The report of the PAC on government accounts submitted to the Parliament said a staggering Tsh700m (about US $\$ 7 \mathrm{~m}$ ) was stolen from the Ministry of Community Developments, Women Affairs and Children in year 2001 through computer-assisted fraud while another Tsh $300 \mathrm{~m}$ (about US $\$ 3 \mathrm{~m}$ ) disappeared from the Prime Minister's Office through similar holes. This was made publicly know by the PAC chairman, adding that in recent days there has been a surge of 
thefts of public funds through the use of computers. The PAC chairman warned in his report that the traditional method of auditing by going through various financial documents was obsolete, and that computer fraud was too loosely regulated because most of the government's auditors lacked the necessary computer security skills to trail suspects. The report finally cautioned that auditors would continue having a hard time trying to detect fraud if the government does not equip them with the necessary IT security skills. And recommended that the government needed to urgently address the computer security issues following fears that the high-tech fraud could now be widespread.

2. In another incident, it was reported that the lone Tanzania electric utility firm, Tanzania Electricity Supply Company (TANESCO) suffered a severe loss due to poor information systems (IS) management. This made publicly known by the President of the United Republic of Tanzania, Benjamin William Mkapa, when addressing the nation in April 2002 [12]. The president noted that in audit reports carried out by two different and independent International Auditing Companies all showed that there was money loss through computer systems. The Auditing Companies that were involved in auditing TANESCO's financial reports at different times are Deloitte Touche Tohmatsu and KPMG, both are Swiss based International consulting and auditing firms. For instance, the President cited out that KPMG revealed in its report that 36 percent of revenue from the pre-paid (LUKU) computer system did not feature in any of the company reports since 1995 . The head of state noted in his speech that in the period covering 1995 to 2000 , the company recorded an aggregate loss amounting to more than Tsh125b (about US $\$ 125 \mathrm{~m}$ ). Information management systems security problems contributed significantly to this loss. Following this huge loss of money, the government had to dismiss the entire Company's management and replace it with a hired South African based NETGroup solutions management to run the company and rectify the problems.

3. In October 2001, KPMG Forensic consulting firm, conducted a fraud survey to 400 public and private companies in East African countries, Kenya, Tanzania, and Uganda. In its final report, East Africa Fraud Survey 2002 [5], it is indicated that 82 percent of respondents considered their computer and information systems to be a potential security risk. The report cited measures used by these companies against computer risks as including access logs, firewalls, passwords and others. Figure 2 shows the typical responses on the use of these security measures. The report further indicated that ownership of intellectual property was, also, considered to be at risk for fraud as shown in Figure 3. The respondents in the report cited Tanzania as one of the four major countries that have experienced 
international fraud. Others include United States of America, United Kingdom, and South Africa.

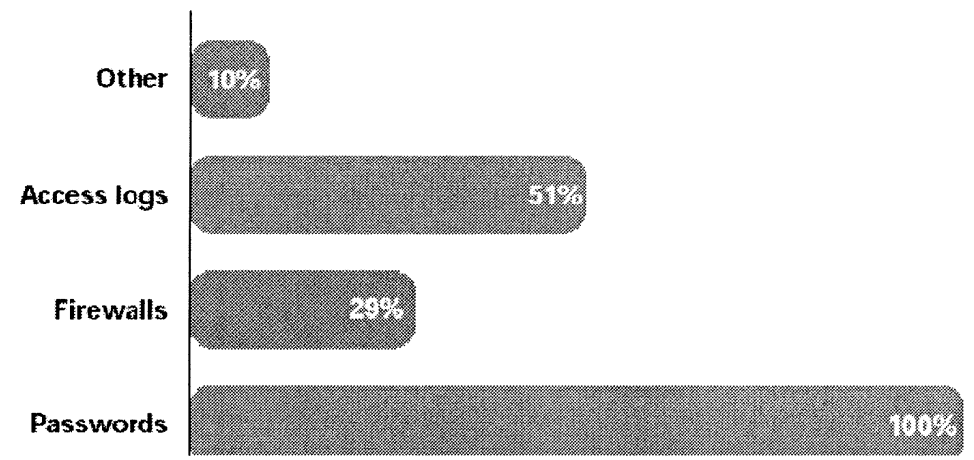

Figure 2. Measures used against computer risks [5, pp.18]

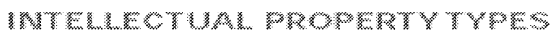

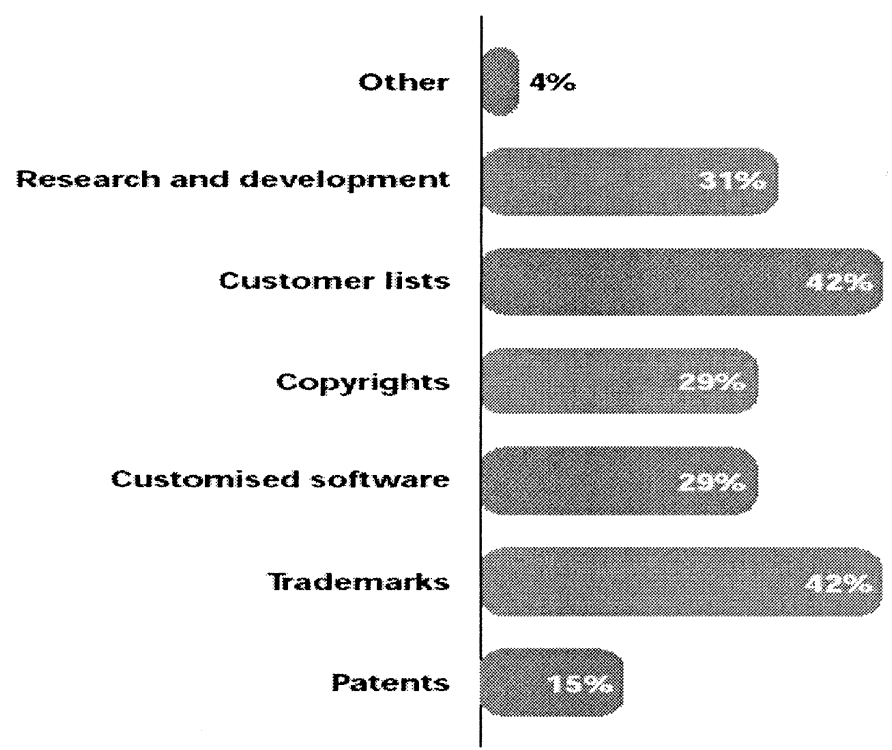

Figure 3. Fraud on Intellectual property [5, pp. 19]

\section{OUR NEXT STEP}

Having observed and learned from the current situation, we are developing an IT security curricula-based approach not only for Tanzania, but also that can be adapted by any other developing country with similar 
environment as that of Tanzania. We understand, however, that one cannot devise a universal approach that can suite all the varying security needs of different computer systems users in every country. In view of this, we have narrowed our research work to focus on security education at an undergraduate level. One of the reasons behind this choice is that most of the practicing computer systems administrators/managers in Tanzania are, at least, holders of bachelors' degrees in various disciplines (see course and seminar evaluations). Second, it is at this level of education where students get minimum qualifications and skills required to enter into the real world security practices.

In collaboration with the Department of Computer Science and the Department of Computer Engineering and Information Technology at the University of Dar es Salaam, Tanzania, we plan to launch a new Degree Program in IT Security at the University. Plans are underway to launch the Program in the 2004/2005 academic year. The Program will attract mainly students coming direct from advanced secondary education with a sound background in science subjects, especially, physics and mathematics. Inservice students from the industry with adequate experience with IT/IS systems shall be encouraged to apply.

This approach is likely to produce IT security professionals who can manage IT systems securely, do research and development projects on IT security, and routinely teach others on security awareness at their respective working places.

\section{CONCLUSION}

We came to learn during our field work in Tanzania, and this is supported by Miller's report to Sida [7] that, one of the differences between Tanzania and other Southern Africa Development Community (SADC) countries is the proliferation of Internet cafés, particularly in Dar es Salaam but also elsewhere. It is very difficult to give the exact figure for the number of Internet cafés in Tanzania because they are mushrooming on a tremendous scale. However, the number was estimated to 1000 plus as of November 2001 [7] most of them in Dar es Salaam, which is the business capital of Tanzania. Retail Internet surfing charges in most cafes in Dar Es Salaam recently dropped from roughly US\$1 to US $\$ 0.5$, that is equivalent to Tsh 1000.00 and Tsh500.00 respectively per hour, but this is still enough to meet the operating costs and also make a little profit. The bulk of clients in most cafés are young people, business people, office workers, students and academics. E-mail services are the most popular at Internet cafés, followed by general website surfing. While a number of people go to make telephone 
calls abroad which is cheap via the net, others go to the cafes on e-business missions but the proportion in this category is relatively small.

Again all these sorts of statistics bring security concerns on how to approach issues of security education to the kids and teenagers in this region. We suggest that a separate study be carried out to see how this can best be dealt with. We have, also, noticed that there is a category of other professionals out there such as lawyers, accountants, nurses and doctors, journalists, schoolteachers, and even politicians who are working with computers and computer systems everyday without proper security awareness training. To this end, we plan to have frequent IT security training and awareness programmes and seminars to discuss security issues for improved awareness.

Should Tanzania get connected to SAT-3 network backbone [10], chances are that many more companies, business organisations, colleges and schools, government agencies and individuals at home will subscribe to the Internet and get reliable access to the world wide web. On the one hand this shall be a blessing to the country since citizens shall be able to share networked information resources with the rest of the networked world. On the other hand, this shall create a big challenge to the country on how to best safeguard the critical information systems infrastructures they are putting in place now against various threats, especially, Internet-based threats. To this end we are of the opinion of the old adage that "Prevention is better than Cure", and that it is high time for Tanzania and similar countries do something in advance as far as IT security is concerned. This stands to reason for our approach to introduce IT security education programs in developing countries such as Tanzania.

Serious security breach incidents like ones cited in this paper are indication that security education is needed in this region. We strongly believe that Universities in developing countries have a role to play to prepare a cadre of IT security workforce, and in raise security awareness in their respective countries.

\section{REFERENCES}

1. Accenture, Markle Foundation, \& United Nations Development Programme (UNDP). Creating a Development Dynamic - Final Report of the Digital Opportunity Initiative: A Global Call to Action, 2001. Also, available at http://www.opt-init.org/framework/pages/contents.html

2. Alec Yasinsac; Information Security Curricula in Computer Science Departments: Theory and Practice, Department of Computer Science Florida State University, Journal of Computer Security, January 2002. 
3. Cynthia Irvine, Shiu-Kai Chin, and Deborah Frincke, "Integrating Security into the curriculum”, IEEE Computer, December 98, Vol. 31, Num 12.

4. Daily News Tanzania Newspaper, " $1 \mathrm{bn} /-$ Stolen through computer fraud, Says PAC", of Thursday, June 13, 2002. Available at http://www.dailynews.co.tz/full.asp?ID=120\&PubID=1

5. KPMG, "East Africa Fraud Survey 2002”. At http://www.kpmg.co.ke/

6. Lamtrac AB, Survey of the Need for a Vocational Training Programme for ICT Professionals in Tanzania Final Report, January 2001. Also available at http://www.ethinktanktz.org/esecretariat/DocArchive/Final\%20report\%20ITSurvey.pdf

7. Miller Esselaar and Associates; A Country ICT Survey for Tanzania Final Report for Sida, November 2001. Also available at http://www.sida.se/Sida/articles/94009499/9481/tanrep.pdf

8. National ICT Policy of Tanzania (First order draft [v3.2e]), Ministry of Communications and Transport, The United Republic of Tanzania. Also available at http://www.moct.go.tz/ict/zerothorder.pdf

9. NIST Special Publication 800-16: Information Technology Security Training Requirements: A Role- and Performance-Based Model. April 1998.

10. SAT-3/WASC/SAFE Project. Also available at http://www.safe-sat3.co.za/

11. Tanzania Communications Commission (TCC), http://www.tcc.go.tz/

12. The Guardian Newspaper, "TANESCO mismanaged, funds misused - Mkapa", of Tuesday, April 30, 2002. Available at http://www.ippmedia.com/guardian/2002/04/30/guardian1.asp

13. The Tanzania Development Vision 2025: Planning Commission, The United Republic of Tanzania, 1999. At http://www.tanzania.go.tz/vission_2025f.html 